\title{
Radical Constructivism: Historical Roots and Contemporary Debate
}

\author{
Simone Cheli \\ School of Human Health Sciences, University of Florence, Florence, Italy
}

Radical Constructivism is an epistemological position stating that knowledge is an agent's active and dynamic construction, and its own value is established by its viability in the agent's world of experience rather than in comparison to an external reality. The concept of Radical Constructivism was coined by Ernst von Glasersfeld (Munich, Germany, 1917 - Leverett, Massachusetts, 2010) in order to highlight the need for a radical perspective on constructivist epistemology, in opposition to any kind of weak or strong realism. Von Glasersfeld aimed to emphasize that knowledge is subjectively constructed rather than objectively perceived through senses. In its original form, Radical Constructivism does not include any tenet about the outside reality, and so does not present a formal metaphysics. It claims that constructivism must be an unconventional approach to knowledge that, without denying the existence of reality, looks at our constructions of experience from a Darwinian adaptation point of view. Historically speaking, von Glasersfeld and other scholars consider three main thinkers as forerunners: (i) Giambattista Vico and his attempt to overcome the debate between skepticism and dogmatism; (ii) George Barkeley and his definition of perception and knowledge; (iii) Jean Piaget and his dynamic and adaptive construction of intelligence.

In the last twenty years, Radical Constructivism has often be framed as an umbrella term including different types of constructivist theories and statements about epistemology, psychology and education. Even if such a broad definition of Radical Constructivism could not be correct, a few perspectives on constructivist tenets must be taken into account. On the one hand, authors such as Heinz von Foerster, Humberto Maturana, Francisco Varela has repeatedly referred to von Glasersfeld in debating and extending the family of constructivist approaches. On the other hand, second order cybernetics, autopoiesis, enaction and other theories developed by these very authors share many assumptions and statements with Radical Constructivism. In such a broader sense, Radical Constructivism turns out to be a manifesto so as to encourage and sustain a rigorous constructivist approach to epistemology and education.

Despite its crucial role in promoting a constructivist epistemology, Radical Constructivism received two main criticisms: (i) it may be considered a solipsist point of view on knowledge and reality; (ii) it may have been viewed as a highly abstract epistemology that is difficult to be operationalized.

\section{Table of Contents}


1. Historical Background
a. Ancient Roots
b. Giambattista Vico
c. George Berkely
d. Jean Piaget

2. Cornerstones of Constructivist Epistemology
a. Cybernetics and Second Order Cybernetics
b. Personal Construct Psychology
c. Italian Operational School
d. Autopoiesis of Living Systems

3. The Foundations of Radical Constructivism
a. Life and Works of Ernst von Glasersfeld
b. Objectivity and Constructivism
c. The Construction of Knowledge
d. The Pivotal Role of Viability

4. Development and Applications
a. Education
b. Other Fields

5. Objections and Criticisms
a. Solipsism
b. Abstractedness

\section{References and Further Reading}

\section{Historical Background}

\section{a. Ancient Roots}

Ernst von Glasersfeld and other scholars have tried to trace a few constructivist tenets back over the history of philosophy. Such a historical tracing back stands on two main claims: (i) constructivist epistemology represents a step out from the philosophical tradition, especially from the realist argument that true knowledge can be distinguished from false belief by comparing human perception and external reality; (ii) a minority of philosophers tried to reject such an argument and were highly opposed or disregarded until the modern times (von Glasersfeld, 1995). Indeed, the Western tradition is frequently characterized by arguments against non-realist theory of knowledge and truth. The most frequent sources when looking for ancient forerunners of Radical Constructivism are the PreSocratics, and especially Skeptics and Sophists. On the one hand, the Skeptics collected innumerable examples to demonstrate the unreliability of the human senses, which could not be trusted to provide a true picture of the real world. On the other hand, Sophists reaffirmed that knowledge's constraints and possibilities are due to the knower him/her-self. As Protagoras stated: "Of all things the measure is man, of the things that are, that they are, and of things that are not, that they are not." (DK80b1). 
Scholars directly or indirectly referring to Radical Constructivism also highlighted a commonality between such an epistemology and many Eastern sources. Embodied Cognition and Enaction approaches have reported how Buddhist epistemology can be seen as an original integration of empiricism and non-dualism that anticipates a few constructivist dimensions (Varela, Thomson \& Rosch, 1991).

\section{b. Giambattista Vico}

The Italian philosopher Giambattista Vico (1668-1744) represents for von Glasersfeld the very first who explicitly defined and argued for a constructivist epistemology. Traditionally speaking, he is considered the first to assume that the course of and the way we conceptualize history depend on the different schemata of thought in different historical periods. The historian (and man generally speaking) turns out to be an active agent who shapes history and so knowledge. When dealing with and criticizing the work of Descartes, Vico described an antithesis between the dogmatism of the "cogito ergo sum" and Skepticism as the impossibility of a certain knowledge. Vico realized that the way out from this dilemma was in considering that "verum est ipsum factum", to be true is the same as to be made. Since man is the active constructor of his own knowledge, true and made are interchangeable terms (Vico, 1998). From a Radical Constructivism point of view, Vico has progressively become the first who breached the traditional realism, questioning the relationship between observers, and observed, even if he never denied an ulterior reality.

\section{c. George Berkeley}

George Berkely (1685-1753) plays an essential role in understanding the Radical Constructivism background, as the main referent of an empiricist tenet affirming how the things we perceive are the results of our perceptual activity and cannot be said to have existence in themselves. Berkeley revolutionized the traditional conceptualization of perception where something must exist before I can perceive it. When reflecting on human vision, he demonstrated that different perspectives construe different objects: the objects seen when flying on an airplane are not the same as those seen by walking on the earth. On the one hand, once perceived, the idea of a thing can be represented and named to serve in other circumstances. On the other hand, general ideas do not exist, because what we perceive is always a particular individual. There is no such thing as a pre-existing set of perceived and ideal objects. The objects are what we perceive and conceive from time to time. Radical Constructivism agrees with Berkeley that it is unintelligible to attribute existence to anything that cannot be perceived.

\section{d. Jean Piaget}

The theory of knowledge and intelligence Jean Piaget (1896-1980) developed represents a crucial cornerstone in Radical Constructivism and in the most of the constructivist approaches. Two main assumptions of Piaget's theory of cognitive development must be taken into account when reflecting on constructivism. Firstly, human intelligence is a self-organizing complex of processes. "The mind organizes the world by organizing itself" (Piaget, 1937, p. 311), that is that organisms shape and coordinate their experience and, in doing so, transform it into a structured and meaningful world. Secondly, the cognitive development is described as the dynamic result of the intertwined processes 
of assimilation and accommodation between the organism and its environment. These two processes define a sort of expanding equilibration, which is an increase in the range of perturbations the organism is able to eliminate. Such perturbations refer both to the individual conceptual structures and to the domain of social interactions. Piaget's original theory of development served as the epistemological (and biological) defense of von Glasersfeld's Radical Constructivism against the risk of solipsism. The realist argument about true knowledge (in the sense that it matches an objective reality) is replaced by the intelligence's ability to progressively equilibrate the perturbations between its own organism and the surrounding environment.

\section{Cornerstones of Constructivist Epistemology}

\section{a. Cybernetics and Second Order Cybernetics}

The first contemporary attempt to define an epistemology that is based on constructivist assumptions

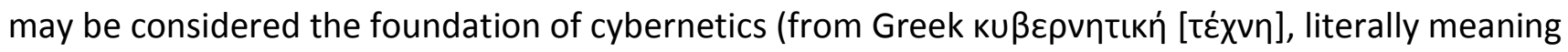
[the art of] steering, specifically a ship), a comprehensive discipline aimed to foster the understanding of self-regulating (animal and mechanical) systems. Despite the first formulations of this novel discipline were mostly referring to mathematical theories, the debate attracted different thinkers. The Macy Conferences on cybernetics (1946-1953) were a multidisciplinary debate around what was later called as the science and the art of understanding understanding (Pias, 2003). Such conferences extended the meaning and the field of cybernetics involving famous natural (e.g. Norbert Wiener, John von Neuman, Heinz von Foerster, etc.) and social scientists (e.g. Margaret Mead, Gregory Bateson, Kurt Lewin, etc.). They all recognized the need to define a common language in modern science as the result of a reflexive analysis of the patterns of understanding and communication of the agents involved in any observations. Cybernetics turns out to be the study of the self-regulating processes that a system applies in order to define and maintain its own equilibrium. It can be considered a way of thinking and mentalizing knowledge rather than a collection of facts and statements. What is called cybernetics arose when reflecting on those systems characterized by a circular causality that is a close signaling loop where action by the system generates some change in its environment and that change is reflected in the system in some manner that triggers a system change. The idea of a circular feedback revolutionizing and shaping the simple linear relationship between input and output opened to a wide range of arguments and objects of study, that were all referring to self-organizing systems. Approximately between 1968 and 1975, Margaret Mead (19011978) and Heinz von Foerster (1911-2002) introduced the so-called second order cybernetics, or the cybernetics of cybernetics. This new type of cybernetics was intended to shift the focus from the observed systems to the observing systems, and so coherently extending and applying the foundative assumptions of the Macy Conferences. Second order cybernetics turned out to be a critique of realism and objectivity and promote an epistemological revolution as a radically reflexive form of science, where observers enter their domains of observation, describing their own observing and selforganizing processes (von Foerster, 2002). Von Foerster and Mead always recognized how contemporary theories of Maturana's and Varela's autopoiesis and von Glasersfeld's Radical 
Constructivism were interconnected with and in support of their own theorizing. All these scholars explicitly aimed to formalize a transdisciplinary approach to the study of self-organizing systems that breaks with the traditional assumptions of objectivity and realism, and affirms the relevance of observing processes in any field of science.

\section{b. Personal Construct Psychology}

The constructivist theory of psychology developed by George Kelly (1905-1967), namely personal construct psychology, represents an anomalous source in Radical Constructivism. It is a minor, even if recurrent, reference in von Glasersfeld's work and almost absent in other constructivist theories. At the same time, the recent developments of personal construct psychology frequently refer to Radical Constructivism, so becoming one of the most relevant field of application of von Glasersfeld's theory. George Kelly can be defined one of the few psychologists who tried to consider human knowledge and experience outside the traditional realism. Three main assumptions can clarify the transferability of personal construct psychology to constructivist epistemology: (i) the identity between man and scientist, in terms of considering the human experience an attempt to predict and control; (ii) the selforganizing processes of human constructions' systems that, in a Piagetian manner, organize themselves so as to make the world meaningful; (iii) the creative capacity of living systems in representing the environment and not simply responding to it (Kelly, 1992).

\section{c. Italian Operational School}

The only one von Glasersfeld clearly and repeatedly defined a master was Silvio Ceccato (1914-1997), the leader of a multidisciplinary group of researchers (later called Scuola Operativa Italiana, Italian Operational School) involved in cybernetics, linguistics and artificial intelligence. Ernst von Glasersfeld joined for fifteen years (1947-1962) the Ceccato's group and discussed together with its participants a radical formulation of constructivism. The efforts of Ceccato and his colleagues were aimed to transpose an operational and cybernetics theory of language and communication to two artificial intelligence projects: (i) a mechanical cross-translation of different languages; (ii) a mechanical reporter, as a machine that observes and describes events in its environment. The theory developed by Ceccato clearly describes a pattern of cognitive and communicative processes highlighting the circular causation of human experience. The theoretical premise was a critical objection to the philosophical tradition Ceccato considered epistemologically biased. He assumed that, by negating the circularity and self-organizing structure of each and every philosophical statement, the most of the traditional schools and approaches play what he calls a theoretical-epistemological game (Teocono), that is a tautological process implicitly validating the player's premises and insistently stating his/her objectivity (Ceccato, 1949). The Italian Operational School tried to went on, stating that: (i) despite we produce the products of our mental operations, they do not seem to be arbitrary; (ii) taken for granted a contextualized and punctuated construction of human experience, the analysis of the processes involved has to be based on moments of attention; (iii) abstracted categories result from the application of a state of attention to itself. Even if these are not the only assumptions and statements of the Italian Operational Schools, were the ones von Glasersfeld especially focused on and tried to interconnect with the work of Piaget and other theorists, in developing Radical Constructivism. 


\section{d. Autopoiesis of Living Systems}

Once we assume that words cannot refer to things that exist independently, but only to representations of the experiences of observer and observed, speaker and hearer, it becomes evident that communication and knowledge pertain to what Humberto Maturana (1928-) and Francisco Varela (1946-2001) define a consensual domain. In order to understand the meaning of such a consensual domain, we have to consider the basic assumptions of the theory of autopoiesis these two biologists developed, influencing and channelizing all the constructivist approaches to epistemology. Maturana and Varela were intended to answer to a general question about what a living system is, or better how it maintains and pursues a kind of organization we are used to calling life (Maturana \& Varela, 1980). They precisely motivated how a biological system is based on a pattern of circular causation: it is autonomous, self-referring, self-constructing, and informationally closed. They labelled

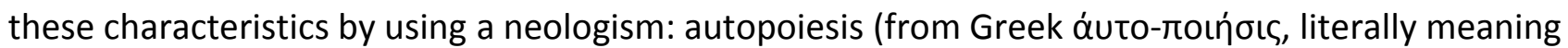
self-creation). An autopoietic system is a system organized as a network of processes of production, transformation and destruction of the very components that, in circular manner, regenerate the network of processes themselves. It is also defined by its specific and concrete unity referring to a specific and concrete topological domain where the network of processes are realized. Despite this theory was built on and tested within a biological framework, it offers the epistemological tools for understanding complex human experiences from a transdisciplinary point of view. On the one hand, it describes the cognitive domain of an autopoietic system as the whole of all the interactions in which it can move without loss of identity, and so relating cognition to the maintenance of self-definition. On the other hand, Maturana and Varela explain how, whenever the conduct of two or more systems is such that the conduct of each one is the function of the conduct of the others, these systems are constituting a structural coupling which a consensual domain pertains to. Therefore, the consensual (or communicative) domain is the ongoing result of the intertwined interactions which, although the conduct of each system is internally determined by its autopoietic organization, are sources of reciprocal and compensable transformations. Maturana and Varela offered to constructivist epistemology (and especially to Radical Constructivism) a highly complex and comprehensive theoretical justification of circularity. They characterized circularity in terms of autonomy and closure, which are indicating that the outside may perturb the equilibrium maintained by an autopoietic system. There is not a linear input-output relationship, but rather a homeostatic process. Moreover, by extending their reflections on cognitive and consensual domains, they offer crucial theoretical tools for developing a constructivist look at ethics and human relationships. Autonomy turns out to be the premise, rather than the logical opposite of sociality. Therefore, ethics may refer to a reflexive practice enacted inside a consensual domain where at least two autopoietic systems are pursuing a structural coupling.

\section{The Foundations of Radical Constructivism}

\section{a. The Life and Works of Ernst von Glasersfeld}


Ernst von Glasersfel (1917-2010) was Emeritus Professor of Psychology at the University of Georgia, Research Associate at the Scientific Research Institute, and Adjunct Professor in the Department of Psychology at the University of Massachusetts Amherst. He was born in Munich from a Pan-European family and brought up with more than one language from his early years. He was a student of mathematics at the University of Vienna before having to move for the Nazi threat (being his family from Jewish ancestors and politically adverse to the Third Reich). He spent the Second World War years in Ireland where he read James Joyce and through the opening lines of Finnegans Wake discovered Giambattista Vico. He then passed to Italy where he lived for about 15 years (1914-1962) personally knowing and working together with Silvio Ceccato. He served as language analyst at the Milan Center for Cybernetics, and was progressively influenced by the Italian Operational School and the Piaget's theory of development. He directed a language research project for the US Air Force from 1962 to 1970 . He moved to USA and taught as professor of cognitive psychology at the University of Georgia, until he retired in 1987 and become Research Associate at University of Massachusetts. During his life, he published dozens of papers about constructivist epistemology and its applications, especially in the field of education. A few collections of these contributions have been published in several languages. His most famous text is Radical Constructivism. A Way of Knowing and Learning, published in 1995. This masterpiece is an attempt to offer a reasoned source book about constructivism, that may orient the laymen and the scholars to understand and recognize what he called a genuine constructivism. He was aware that after many years theorizing about a constructivist theory of knowledge, his own words (and the words of many constructivist theorists) needed to be clearly organized and explained. We may consider this book, and generally speaking all the Ernst von Glasersfeld's work, an extensive and rigorous reflection on the application of constructivism in the solely field of knowledge and knowing.

\section{b. Objectivity and Constructivism}

Radical Constructivism may be considered an attempt to deal, or better to overcome one of the most crucial problems of traditional philosophy: is our knowledge a true representation of reality? In doing so, Radical Constructivism, as von Glasersfeld intended to do, tries to ground an answer on different (direct and indirect) sources of constructivist epistemology. The foundative premise is that this kind of problem cannot be solved, because we have no direct access to reality and cannot compare our knowledge to it. Indeed, Radical Constructivism "starts from the assumption that knowledge, no matter how it be defined, is in the heads of persons, and that the thinking subject has no alternative but to construct what he or she knows on the basis of his or her own experience" (von Glasersfeld, 1995, p. 1). Constructivist scholars are used to describe their theory as a rational approach to knowledge, in contrast to an intrinsically biased metaphysical attempt to describe reality as it is. On the one hand, von Glasersfeld highlights how difficult may be decentering from our own look at reality and consider it as a possible construction rather than a description of reality. He repeatedly affirmed, as his master Ceccato was used to do, how common and taken for granted is a metaphysical approach to knowledge, and how disregarded and marginalized is a constructivist-like perspective. On the other hand, he aims to demonstrate how the rare forerunners of constructivism debated a few assumptions that became more evidence-based and spread as the modern times approached. Vico, Berkeley and Piaget are the authors von Glasersfeld personally uses in approaching the modern times. 
The Berkeley's way to empiricism clearly supports the constructivist tenet (and the Vico's intuition) that the traditional problem of philosophy (is our knowledge a true representation of reality?) cannot be solved, since we can only compare our ideas to other ideas rather than to what they represent. A pragmatic solution to such a problem that does not avoid the epistemological question is the one by Jean Piaget. The Swiss psychologist and his cognitive theory of development offers to von Glasersfeld and to constructivism a crucial support: true is what works, truth is the ontogenetic result of intelligence's adaptation within its own constraints and possibilities. The acquisition of knowledge is an adaptive process through biological mechanisms and its development cannot be separated from its practical and active role in the agent's experience. From a Piagetian point of view, to know an object means to incorporate the representation of such an object into an action schema. This perspective validates the von Glasersfeld idea that a constructivist epistemology is coherent with the modern scientific method. As George Kelly would say, we can assume an identity between scientist and man, and consider our experience an attempt to make our view of the world meaningful and ready to be operationalized. It is interesting to note that Radical Constructivism. A Way of Knowing and Learning starts quoting a famous von Foerster's adage: objectivity is the delusion that observation can be made without an observer. The relation of knowledge to the real world is intended to be reciprocal, by assuming an identity between man and scientist. Constructivism does not deny the existence of reality, it states that what we categorize as 'external reality' and 'environment' is the result of an active construction defined by a whole of constraints and possibilities arising from what Maturana and Varela define a structural coupling. To the extent that we include the others into our experience, they became part of what we can know and what we cannot.

\section{c. The Construction of Knowledge}

The foundation of a constructivist epistemology extensively draws on the theorists of second order cybernetics and autopoiesis. They become so crucial within the constructivist paradigm, because they extensively tried to balance the self-reference function of knowledge and its socialized and relational counterpart. To understand how Radical Constructivism conceptualizes the construction of knowledge probably means to understand how an autopoietic definition of identity may include a continuous exchange with the environment, even if the external reality is labelled as a constructed category. When dealing with the construction of knowledge, constructivist epistemology describes two intertwined (and inseparable) levels of processes. A first level refers to those processes involved in the construction of concepts: reflection, abstraction, generalization, re-presentation, etc. A second level is intended to formalize how constructivism describes complexes of processes such as communication, learning and science. It is important to stress that, despite the frequent use of cognitively oriented words and language, what constructivist scholars refer to when talking about processes is intended to be a monistic integration of many dualities such as mind-body, rationalemotional, personal-social, etc. Since they assume an active and dynamic role of the agent that cannot be separated from his or her constructions, they imply that the cognitive domain (that is the domain of agent's processes of knowing) is the domain of all the constructions and interactions the agent can enter without the loss of identity (that is of the structure defining the autonomous unity of him/herself). 
When von Glasersfeld wrote that Radical Constructivism. A Way of Knowing and Learning a few attempts to summarize the processes involved in a constructivist theory of knowledge have been published. Three main sources must be taken into account, since they probably represent the most coherent evolution of second order cybernetics and theory of autopoiesis. On the one hand, Heinz von Foerster was progressively proposing enlightening reflections that were orienting (and are still orienting) the most of the advances of constructivist epistemology. He especially highlighted that: (i) we have to consider human cognition without separating presumed low-order and high-order functions, and so fostering the development of a coherent monistic theory of knowledge that underpins the autonomy and complexity of ours; (ii) a second order perspective on cybernetics, epistemology, in one word on humanity presumes a homeostatic living system that organizes itself so as to compute a stable reality (von Foerster, 2002). From a second order cybernetics point of view, observed objects turn out to be a kind of tokens for what von Foerster calls eigen-values or eigenbehaviors (in mathematics an eigen-value is a scalar associated with a given linear transformation of a vector space). The objects of our observation (and of our experience) are a sort of symbolic entity, participating in a network of interactions. Our behaviors are cues of a concatenation processes that reflexively defines our organization. On the other hand, Maturana and Varela developed two personal attempts to advance their theory of autopoiesis. They started their reflection from a kind of identity between the perceptual possibilities of system and the type of structural coupling is establishing with the environment. Their formulation of knowledge deeply refers to what we psychologically call communication and biologically can define as the crossroad between constraints and possibilities. We can talk about knowledge whenever we observe a sufficiently adequate behavior in a domain in which we define by a question (Maturana \& Varela, 1987). They then developed two different perspectives on autopoiesis and living systems. Maturana took the autopoietic function of communication to the extremes, developing a sort of constructivist ontology. He defines an ontological positioning of autopoiesis by assuming that: (i) traditional objectivity is not needed for the generation of a scientific theory, since a subjective perspective has a self-maintaining role; (ii) cognition and self-consciousness arise with language, since a living system depend on its exchange with the environment to perpetuate a necessary homeostasis. His ontology states that nothing exists in distinction and reality arises together with self-consciousness and through a language that is an explanation of the distinction between self and non-self (Maturana, 1988). At the same time, Varela progressively tried to interconnect autopoiesis with Western phenomenology and Buddhist philosophy. Or better the theory of embodied cognition and enaction he developed arose by what he called the breakdown of Western phenomenology. In looking for a comprehensive explanation of human consciousness, he reported the need for a pragmatic and monistic alternative to the phenomenological reduction, which he described as an entirely theoretical process. Enaction refers to a perspective on autonomy that is relationally oriented and cognitively defined by and in situated embodied action. By absorbing the architecture of the Buddhist philosophy, Varela especially focuses on: (i) the assumption that, if everything is in a consensual domain, nothing can be found that has an ultimate or independent existence; (ii) if the self is the circular source of the maintenance of our constraints and possibilities, the Buddhist emptiness, as a pursued state of self-less-ness, may promote a transformative increase of our awareness (Varela, Thomson \& Rosch, 1991). 
Therefore, when Ernst von Glasersfeld started writing Radical Constructivism. A Way of Knowing and Learning there were, at the same time, a few leading threads in and a differentiating proliferation of constructivist epistemology. In the opening chapters, he clearly stresses the need for: (i)

distinguishing constructivism from any kind of realist or ontological positions about external reality or truth; (ii) describing in a rigorous manner the processes involved in knowledge and knowing, as the only field a radical constructivism can talk about. These two goals shaped his theory and strictly defined the unbridgeable distinction between the inside (the construing observer) and the outside (the environment as a black box), and the pivotal role of viability as the Darwinian adaptation of our construction systems. The Radical Constructivism, in the tight sense articulated by von Glasersfeld, shows many commonalities with von Foerster's second order cybernetics, and many differences with Maturana's and Varela's development of the theory of autopoiesis. As we said, von Glasersfeld progressively explores a constructivist conception of knowledge passing from a low-order to a highorder of intertwined processes. The starting points are that; (i) knowledge is not passively received from senses but actively built up by a cognizing agent; (ii) such a process of cognition is not intended to reveal an ontologically defined reality, but rather serves to promote the agent's adaptation, by organizing his or her experience.

By transposing the circularity between sensorimotor knowledge and action, and conceptual knowledge and symbols, von Glasersfeld leads the attention to a crucial question he faced with working together with Ceccato: what kind of operations we carry out in order to see things in the way we see them. Such operations are the constitutive processes of our knowledge and may be better understood integrating the Piaget's theory of mental operation and the operational analysis of moments of attention formulated by Ceccato. In doing so, von Glasersfeld want to highlight how we need to look at usual mental processes described by many authors in a different manner. He want us to remember that we are still talking about knowledge of an object (e.g. an apple) and not about the object itself. Even if von Glasersfeld extensively explains in his work the theory of Piaget, he develops his own theory by especially focusing on the operative dimension (that is a conceptual construction that does not depend on specific sensory material, and so are not observable) of our experience. Whenever we aim to perform an analysis of concept such as change, movement, etc., we are not considering an external reality that is independent of the subject. The concepts that are constitutive of a few mental operations are the subject's tools to manage and organize the flow of experience. Therefore, in describing general processes such as abstraction and representation von Glasersfeld applies a method very similar to the one described by von Foerster and defined as eigen-behavior. The general processes activate a kind of recursive and transformative circularity. What was produced by one cycle of operations is taken as a given content for the next one. The latter can then be coordinated by the former as a new structure to be conceptualized and used as a symbol for the following operations. What we conceive as an organized and definite pattern of symbols, communication and mentalization is the results of a enduring and successive series of operations. In order to make live and experience manageable and pursue an equilibrium, a living system tries to establish regularities in the flow of experience. From a Radical Constructivism point of view, there is not such a thing as the universals. There are recognition matrices and concepts that may help the subject in cutting pieces out of the flow of experience and so to recognize them as belonging to a 
class. And so these classes are deliberatively created as operative model to apply and test. The living systems themselves turn out to be determining factors in the generation of knowledge.

\section{d. The Pivotal Role of Viability}

The reflexive and circular nature of knowledge is the one of a scientific procedure that always passes through cycles of observation, model construction, prediction, and again observation. In facing the assumption of the environment as a sort of black box, Radical Constructivism repeatedly remarks the crucial role of such a cybernetics approach in generating continuous tentative explanations. Second order cybernetics, and partly personal construct psychology, supports Radical Constructivism in underlining three crucial statements: (i) our concepts and conceptual operations and structures are necessarily hypotheses; (ii) all the hypotheses are susceptible to be revised by the subjects themselves; (iii) whenever we consider developmental changes in living systems we have to do that from an eigen-behavior point of view so as not to assume objective and standard patterns. These points may be considered the premises of the pivotal role of viability in Ernst von Glasersfeld's look at constructivism.

Indeed, Radical Constructivism assumes that what saves itself from solipsism is such a construct of viability as the result of considering man a sort of scientist (always formulating and testing hypotheses) and the act of knowing a process of adaptation. Von Glasersfeld repeatedly tried to explain how viability represents his attempt to articulate and refine the Darwinian construct of adaption within his epistemological framework. Firstly, he assumes that no matter off how realist is a theorist's position, there can be no doubt about the fact that an organism has to construct a representation out of its proximal data. Secondly, as soon as the question of truth (i.e. the correspondence between such a representation and what is represented) arises, a Radical Constructivism point of view highlights a tautological dilemma. In order to know if our representation is a true picture of reality we should have the chance to have access both to our representation and to the outside reality before knowing it. Since the only way in which we are supposed to get a glimpse of reality is precisely the way we are intended to check and verify, we find ourselves closed inside a dilemma. Thirdly, von Glasersfeld and many other constructivists transpose this relevant question into the intertwined paths of constraints and possibilities arising from the theory of adaptation. Just as the environment does not cause an organism to have certain characteristics but rather it eliminates the one that knocks against its constraints, there is not a linear causation between representation and reality but rather the maintenance of those representations that do not knock against the black box of environment. The relation between knowledge and the so-called reality is the one between an organism and its environment. Finally, we arrive to the overlapping between Darwinian survival and von Glasersfeld's viability. All the concepts, theories, and, generally speaking, cognitive structures, are viable (i.e. survive) as long as they serve the purposes to which they are put, and reliably help us in achieving such purposes. In any case, the constraints are not intended to be ontologically referred to reality, they are just pragmatically conceived as referents of our experiential processes within a framework of what Piaget was used to call an expanding equilibration. "The fact that some construct has for some time survived experience - or experiments, for that matter-means that up to that point 
it was viable in that it bypassed constraints that were inherent in the range of experience within which we were operating" (von Glasersfeld, 1980, p. 93).

All these assumptions and argumentations have to be referred to the social dimension of experience too. Indeed, if we assume a subjective construction of experience (and so for example of objects, words, signs, etc.), the crucial question of how we can communicate urgently arises. By extending the Piagetian adage that is meaningful whatever works, von Glasersfeld assumes that a person modifies and adapts his or her own concepts as well as the context constrains him or her to do so. The process of looking for regularities and anticipating the future experience we do by ourselves in making an object meaningful, it is assumed to be the same we experience in converging toward a shared meaning with an other person. The process of understanding in the context of communication is the same to the process of knowing in the context of experience. There is an explicit circularity in what von Glasersfeld describes when talking about communication. The viability of my constructions leads to consider the others as a kind of constraint of my experience, and the others are anyway a kind of construction of mine. As with all other constructions, the ways we construe the other turn out to be viable in our experience, or they do not and have to be eliminated. By assuming that communication involves at least two agents, we take for granted that we need the collaboration of the others in order to succeed in fully experiencing as humans. Knowledge may be reframed as conceptual structures that persons, given the range of the here-and-now experience within their tradition of thought and language, consider viable.

\section{Development and Applications}

\section{a. Education}

The field of education may be considered as the area where Radical Constructivism shows the most extensive and differentiated application. On the one hand, von Glasersfeld clearly stated that his theory is concerned only with the field of knowledge and knowing and aims to support people in developing a different way of looking at their own experience. On the other hand, Radical Constructivism has proved to have an influential positioning within the modern framework of education, reporting different and broad applications. Theoretically speaking, Radical Constructivism has been viewed as useful epistemological tool in dealing with the modern philosophy of science and so with the more effective ways in advancing scientific knowledge (Matthews, 1998). The recurring similarities with a few assumptions of frameworks such as Quantum Logic has urged philosophers of science and scientists themselves to include Radical Constructivism in their backgrounds as an abstract and transferable approach to knowledge they may apply in spite of the type and level of development of a scientific theory. Moreover, Radical Constructivism has been (and is still) used as a pedagogical referent in training teachers and supporting the processes of knowing and learning in different levels of education (Tobin, 1993). Since many education programs have been developed on the basis of constructivism, von Glasersfeld's theory can be consider part of the leading paradigms of modern pedagogy. In terms of specific disciplines, mathematics reports the most extensive studies 
about the application of Radical Constructivism in the development of education programs and in the advancement of scientific knowledge.

\section{b. Other Fields}

All the possible applications of Radical Constructivism lied outside the domain of the present discussion. In any case, it may be interesting to report two scientific areas that are influenced by Radical Constructivism. Since constructivism and Radical Constructivism are often confused and considered as overlapping frameworks, we have to include in our discussion a few types of hybridization. The continuous cross-fertilization between Radical Constructivism and theories such as autopoiesis, second-order cybernetics and so on, are extending the applicability of constructivism in different epistemological fields. An area where in the last 20 years we have seen many publications and studies is for sure the one of artificial intelligence, both in terms of extending the theoretical background and of supporting the learning processes of the machines (Drescher, 1991). Moreover, the influence of Radical Constructivism on the development of constructivist epistemology has proven to progressively influence modern psychology, fostering the abandon of a tight realism and monism, especially in the field of psychotherapy (Hayes, 2004).

\section{Objections and Criticisms}

\section{a. Solipsism}

The most probably reported and extensively discussed criticism against Radical Constructivism is the one of solipsisim. Indeed, many scholars highlight how the epistemological position of constructivism, if applied rigorously, may lead to the philosophical statement that only one's own mind can be proved to exist. On the one hand, von Glasersfeld and many of his opponents have rejected a tight definition of solipsism for Radical Constructivism, especially thanks to the pivotal role of viability in construing the black box of environment and other minds. On the other hand, these very opponents have reported many theoretical contradictions between the general anti-objectivist statements of Radical Constructivism, and the practical development of these statements. The basic assumptions is that in articulating the methodological implications of Radical Constructivism within the field of scientific knowledge, the question of reality, sociality and so on cannot be eluded and have led constructivist theorists to conveniently suspend any judgment (Martinez-Delgado, 2002). In spite of the von Glasersfeld's repeated premise that Radical Constructivism can only talk about knowledge, many constructivist theorists such as Maturana and Varela have tried to extend the range of convenience of their theory acroamongss different fields such as biology, sociology, and so on. Von Foerster has also expressed the need for focusing second order cybernetics on social issues and so extending the original arguments. In short, we may assume that a few supporters and many opponents have highlighted two main objections to a tight interpretation of Radical Constructivism: (i) the assumption of transferability of a superordinate epistemology may knock against a few areas of education where different pedagogical tools are needed; (ii) scientific disciplines such as biology and sociology may 
require a different epistemological position, or better may have to go beyond a solely theory of knowledge.

\section{b. Abstractedness}

With the only exception of education, Radical Constructivism and constructivist epistemology seems to face a sort of a crisis. Such a crisis seems to refer to a process of theoretical proliferation and progressive abstractedness that seems to transform Radical Constructivism in a problem-solving tool rather than a coherent and influencing scientific paradigm (Riegler, 2015). By limiting the range of convenience due to its core epistemological premises, Radical Constructivism is seen as a very abstract approach that is difficult to practically and extensively operationalized. The absence of a clear-cut theoretical definition and the tendency to maintain a superordinate and strictly epistemological positioning have established a vicious cycle that seems to reduce the number of publications, especially the ones read and quoted outside constructivist circles. The supporters of Radical Constructivism acknowledges this kind of criticism and try to overcome it fostering the development of a constructivist paradigm.

\section{References and Further Reading}

Ceccato, S. (1949). II Teocono (The Teocono, Translation, E. von Glasersfeld, Methodos, I,1, 55-59). Methodos, I, 1, 34-54.

Diels, H. (1972). Die Fragmente der Vorsokratiker. Rev. Walther Kranz. Berlin: Weidmann.

Drescher, G.L. (1991). Made Up Minds. A Constructivist Approach to Artificial Intelligence. Boston: The MIT Press.

Hayes, S. C. (2004). Acceptance and commitment therapy, relational frame theory, and the third wave of behavioral and cognitive therapies. Behavior Therapy, 35(4):639-665. doi: 10.1016/S0005-

7894(04)80013-3

Kelly, G.A. (1992). The Psychology of Personal Constructs. Volume One: Theory and Personality. London: Routledge.

Martínez-Delgado, A. (2002), Radical constructivism: Between realism and solipsism. Science Education, 86: 840-855. doi:10.1002/sce.10005

Matthews, M.R. (1998). Constructivism in Science Education. A Philosophical Examination. Amsterdam: Springer Science.

Maturana H. R. (1988). Ontology of observing: The biological foundations of self-consciousness and the physical domain of existence. In: Donaldson R. E. (ed.) Texts in cybernetic theory: An in-depth exploration of the thought of Humberto Maturana, William T. Powers, and Ernst von Glasersfeld. American Society for Cybernetics. 
Maturana, H., \& Varela, F. (1980). Autopoiesis and Cognition. The Realization of the Livings. Dordrecth: Reidel.

Maturana, H., \& Varela, F. (1987). The Tree of Knowledge. The Biological Roots of Human Understanding. Boston: Shambala.

Piaget, J. (1937). La Construction du Réel chez l'Enfant (The construction of Reality in the Child, Translation, M.Cook, New York, Basic Books, 1971), Neuchâtel: Delachaux et Niestlé.

Pias, C. (2003). Cybernetics - Kybernetik. The Macy-Conferences 1946-1953. Zürich: Diaphanes.

Riegler A. (2015) What does the future hold for radical constructivism? In: Raskin J. D., Bridges S. K. \& Kahn J. S. (eds.) Studies in meaning 5: Perturbing the status quo in constructivist psychology. Pace University Press, New York.

Steffe, L.P. \& Thomson P.W. (2000). Radical Constructivism in Action. Building on the Pioneering Work of Ernst von Glasersfeld. London: Routledge - Falmer.

Tobin, K.G. (1993). The Practice of Constructivism in Science Education. London: Routledge.

Varela, F., Thompson, E., \& Rosch, E. (1991). The Embodied Mind. Cambridge, MA: MIT Press.

Vico, G. (1988). On the Most Ancient Wisdom of the Italians, Unearthed from the Origins of the Latin Language. Including the Disputations with the Giornale de' Letterata d'Italia. Translated with an Introduction and Notes by L. M. Palmer. Ithaca and London: Cornell University Press.

Von Foerster, H. (2002). Understanding Understanding. Essays on Cybernetics and Cognition. New York: Springer-Verlag.

Von Glasersfeld, E. (1981). The concepts of adaptation and viability in a radical constructivist theory of knowledge. In I. E. Sigel, D. M. Brodzinsky and R. M. Golinkoff (eds), Piagetian Theory and Research. Hillsdale: Erlbaum.

Von Glasersfeld, E. (1995). Radical Constructivism. A Way of Knowing and Learning. London: Routledge - Falmer.

Von Glasersfeld, E. (2007). Key Works in Radical Constructivism. Edited by Marie Larochelle. Rotterdam: Sense Publisher.

\section{Author Information}

Simone Cheli

Email: simone.cheli@unifi.it

University of Florence

Italy 